\title{
REVIEW
}

\section{Advanced analytical electron microscopy for lithium-ion batteries}

\author{
Danna Qian ${ }^{1,2,3}$, Cheng Ma ${ }^{1,3}$, Karren L More ${ }^{1}$, Ying Shirley Meng ${ }^{2}$ and Miaofang $\mathrm{Chi}^{1}$ \\ Lithium-ion batteries are a leading candidate for electric vehicle and smart grid applications. However, further optimizations of \\ the energy/power density, coulombic efficiency and cycle life are still needed, and this requires a thorough understanding of the \\ dynamic evolution of each component and their synergistic behaviors during battery operation. With the capability of resolving \\ the structure and chemistry at an atomic resolution, advanced analytical transmission electron microscopy (AEM) is an ideal \\ technique for this task. The present review paper focuses on recent contributions of this important technique to the fundamental \\ understanding of the electrochemical processes of battery materials. A detailed review of both static (ex situ) and real-time \\ (in situ) studies will be given, and issues that still need to be addressed will be discussed. \\ NPG Asia Materials (2015) 7, e193; doi:10.1038/am.2015.50; published online 26 June 2015
}

\section{INTRODUCTION}

To implement the commercialization of lithium-ion batteries in electric vehicles and smart grid systems, further improvements are required, especially with respect to the energy/power density, coulombic efficiency and cycle life. These parameters primarily depend on the diffusion of lithium-metal ions, electron transport, structure and chemical dynamics of the electrode/electrolyte materials, among others. During electrochemical cycling, significant changes in the material structure and elemental distributions occur, including ion relocation, lattice expansion/contraction, phase transition and structure/surface reconstruction. These changes could substantially influence ion and electron transport and affect the performance of the entire battery system. Understanding the structure-property relationships for each component and their synergistic behaviors during electrochemical processes is, therefore, essential for the design of new battery materials and the optimization of existing systems.

Although many analysis techniques (for example, X-ray diffraction, $\mathrm{X}$-ray absorption spectroscopy, neutron diffraction, nuclear magnetic resonance and so on) have been employed for such studies, most of them can acquire only spatially averaged information. Nevertheless, the structural and chemical evolution of battery materials upon electrochemical cycling can often be linked to specific nanofeatures, such as defects, interfaces and surfaces. As a result, techniques based on analytical transmission electron microscopy (AEM) are ideal tools to study these issues. The capability of AEM to precisely probe the structural/chemical evolutions at an ultrahigh spatial resolution frequently provides insight that cannot be obtained directly using macroscopic characterization methods.
In this review article, recent AEM developments to study lithiumion batteries will be highlighted, and the implementation of these techniques will be described using representative examples demonstrating how advanced microscopy methods can significantly promote the fundamental understanding of battery materials. Both the static (ex situ) studies using high-resolution electron microscopy and the recently developed dynamic (in situ/operando) AEM techniques for battery research will be covered. Ideas for future research directions will also be discussed.

\section{RECENT ADVANCEMENTS IN AEM CAPABILITIES}

Over the past two decades, a number of significant improvements in AEM have provided substantial opportunities for understanding the working mechanisms of battery materials. Of these capabilities, the most important is the direct observation of the atom positions, chemical bonds and ion/electron distributions at the atomic scale (Figure 1). ${ }^{1-4}$ By taking advantage of the various scattering processes that occur between the incoming electrons and atoms in the material, analytical imaging techniques with sensitivities to different structural and chemical information can be simultaneously applied using multiple annular detectors in the scanning transmission electron microscopy (STEM) mode. A high-angle annular dark-field (HAADF) detector provides an image exhibiting a contrast that is proportional to the atomic number $\left(\sim Z^{1.7}\right)$ of the atoms, whereas an annular brightfield $(\mathrm{ABF})$ detector provides an image contrast proportional to $\sim Z^{-1 / 3}$, which is ideal for imaging light elements such as lithium., A STEM BF detector, which collects elastically scattered electrons, provides phase contrast images that are equivalent to standard BF transmission electron microscopy (TEM) images. ${ }^{7}$ By contrast, low-

${ }^{1}$ Center for Nanophase Materials Sciences, Oak Ridge National Laboratory, Oak Ridge, TN, USA and ${ }^{2}$ Department of NanoEngineering, University of California San Diego, La Jolla, CA, USA

${ }^{3}$ These authors contributed equally to this work.

Correspondence: Dr M Chi, Center for Nanophase Materials Sciences, Oak Ridge National Laboratory, 1 Bethel Valley Road, Oak Ridge, TN 37831, USA.

E-mail: chim@ornl.gov

Received 6 March 2015; revised 9 April 2015; accepted 13 April 2015 

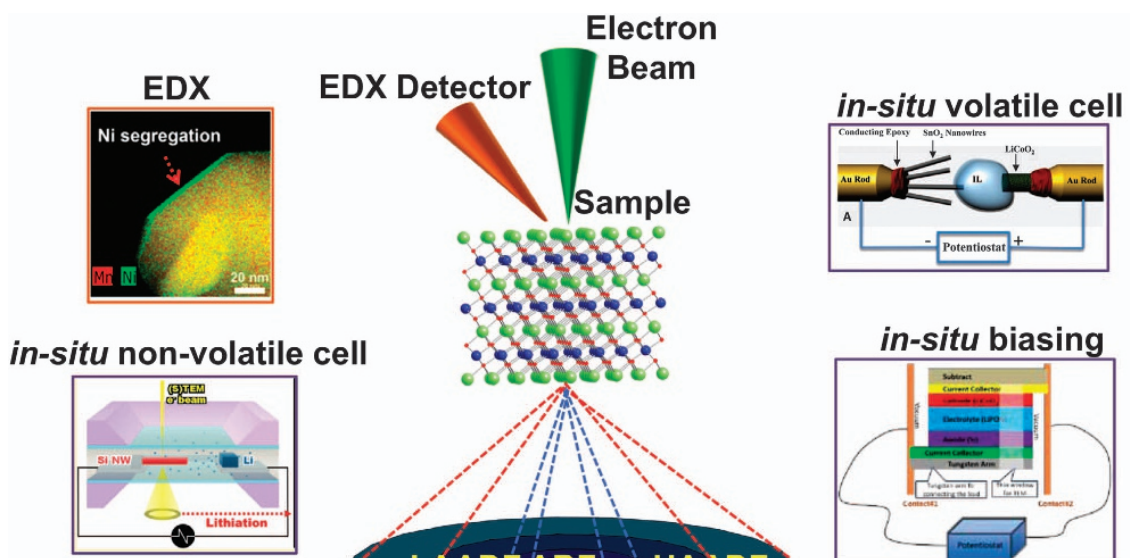

EELS

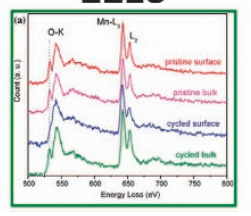

\section{LAADF ABF HAADF}
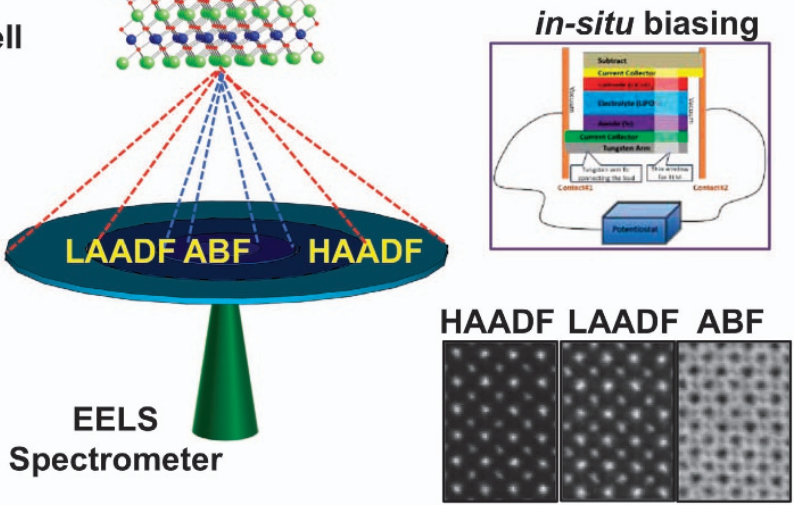

Figure 1 State-of-the-art (S)TEM techniques and their applications in battery research. ${ }^{26,62,63,69}$ All figures have been reproduced with permission. STEM, scanning transmission electron microscopy; TEM, transmission electron microscopy.

angle annular dark-field imaging forms images by collecting both elastically and inelastically scattered electrons that contribute to the detected signal, and it allows the mapping of strain fields in materials at an atomic resolution. ${ }^{8}$ In addition to these imaging techniques, electron energy-loss spectroscopy (EELS) can be used to probe the electronic structures of materials along with elemental analysis. ${ }^{9,10}$ In particular, the EELS spectrum imaging mode provides the unprecedented benefit of quantitatively probing both the chemistry and structure of the nanofeatures at sub- $\AA$ resolution. ${ }^{11,12}$ With the recent development of monochromators for electron guns, an energy resolution of $10 \mathrm{meV}$ can be achieved for the EELS analysis, which not only enables the study of the electronic structure and atomic bonds with a much higher accuracy but also provides the capability of interrogating vibrational features in solid materials. ${ }^{1,13}$

Improvements in ultrahigh spatial and energy resolutions have been accompanied by remarkable advances of in situ TEM techniques, which enable the real-time observation of the dynamic structural and chemical evolution in materials under a variety of external stimuli or battery operating conditions. The progress in this field is evident, as demonstrated by the success of in situ mechanical testing or heating while maintaining a high spatial resolution, ${ }^{14,15}$ by the imaging of reaction processes in gases and liquids, ${ }^{16-19}$ by the observations of reactions and phase transformations upon external biasing ${ }^{20,21}$ and so on. In addition, the newly developed CMOS camera, which enables the direct electron detection and fast image acquisition at over 400 frames per second for $1 \times 1 \mathrm{~K}$ images, has significantly advanced the capability to observe fast reactions in real time. ${ }^{22}$ These noteworthy developments in electron microscopy have created unparalleled opportunities for understanding the working mechanism of battery materials, which will eventually accelerate the design/discovery of novel battery materials and systems.

\section{HIGH-RESOLUTION AEM OF BATTERY MATERIALS}

The combination of sub-§̊-resolution STEM imaging and EELS has provided vital insight into the relationship between structure, composition and properties of different battery components. The importance of this research will be discussed below from the perspectives of the electrode and solid electrolyte materials.

\section{Electrode materials}

On the basis of the reaction chemistry, electrode materials can be divided into three types: intercalation, conversion and alloying materials. Intercalation materials, which are most commonly used as the cathodes, are typically transition metal oxides. The host structure does not change during the insertion and extraction of the lithiummetal ions. Conversion materials are mostly transition metal oxides and fluorides, where the cycling is associated with a change in the host structure and the formation of transition metal nanoparticles or lithium oxides. Alloying materials form an alloy with the lithium metal during cycling, which is often accompanied by a volume change. Although AEM has played a crucial role in understanding the electrochemical behaviors of all three of these types of materials, this section will primarily focus on the AEM studies of the intercalation materials, which have the broadest interest for both fundamental studies and commercial applications.

Among the intercalation materials, Li-excess layered compounds, high-voltage spinels and olivines have received the most significant attention. Although their overall structure remains the same during charge/discharge, the changes in the $\mathrm{Li}$ concentration are always accompanied by localized structural modifications, such as expansion/ contraction of the lattice, phase transitions, surface reconstruction and so on. These phenomena are typically the key to comprehend the electrochemical behavior of the materials. With a sub- $\AA$ spatial resolution, advanced electron microscopy provides unique insight into these processes.

Recent microscopy studies have significantly advanced research of the Li-excess layered materials, $x \mathrm{Li}_{2} \mathrm{MnO}_{3}-(1-x) \mathrm{LiMO}_{2}(\mathrm{M}=\mathrm{Mn}$, $\mathrm{Ni}, \mathrm{Co}, \mathrm{Fe}, \mathrm{Cr}$ and so on), which possess the highest capacity of all of the intercalation cathode materials. Two important characteristics have been debated for this family of materials: the crystal structure of the pristine material and the microscopic origin for the performance degradation upon cycling. The disagreement on the former one lies in 
the phase constitution: the pristine material could either consist of closely intertwined $R \overline{3} \mathrm{~m}$ and $C 2 / \mathrm{m}$ phases or simply be a single-phase solid solution with the $C 2 / m$ structure. X-ray and neutron diffraction cannot directly distinguish between these two structures due to the overlapping diffraction peaks and the weakness of the superlattice diffraction. However, they can be easily differentiated via atomicresolution HAADF-STEM imaging, and the three-time periodicity of the atomic configuration along the $[1 \overline{1} 0]$ zone axis of the $C 2 / m$ structure which is absent in the $R \overline{3} \mathrm{~m}$ phase. On the basis of this fact, Jarvis et al. ${ }^{23}$ reported that their Li-excess layered material is a solid solution. By contrast, Bareno et al. ${ }^{24}$ found a locally $\mathrm{Li}_{2} \mathrm{MnO}_{3}$-like region within the parent rhombohedral Li-excess layered material structure, and Boulineau et al. ${ }^{25}$ observed the coexistence of the two phases, $R \overline{3} m$ and $C 2 / m$, with the same nominal composition. The precise structural determination in these microscopy studies reconciled the long-standing debate. Instead of exhibiting a definitive structure, the pristine material could exhibit different phase constitutions depending on the transition metal species, bulk stoichiometry, synthesis method and calcination temperature.

The second question, that is, the performance degradation mechanism during cycling, is directly related to the main obstacle to the commercialization of this promising cathode material. Through combined electron microscopy studies and theoretical calculations, Meng et al. identified the most important structural origin for the performance degradation. ${ }^{26-29}$ They found that due to the diffusion of the transition-metal (TM) ions to stable sites within the Li-rich intercalation planes (purple arrows in Figures $2 \mathrm{a}$ and $\mathrm{b}$ ), a defective TM-rich spinel surface layer formed after cycling. Similar observations have been made by other research groups. ${ }^{25,30}$ This $\sim 1-2$-nm-thick TM-rich surface layer has been speculated to be the primary cause for the voltage decay, ${ }^{28}$ and a novel oxygen-vacancy-assisted TM migration mechanism has been proposed to facilitate its formation. However, different opinions also exist. Boulineau et al. ${ }^{30}$ proposed that a surface $\mathrm{Ni} / \mathrm{Mn}$ segregation, instead of the surface phase transformation, is the origin for the performance degradation. Moreover, Gu et al. ${ }^{31}$ suggested that the non-uniform TM distributions and the nanophase separation also influence the voltage evolution. Despite such a disagreement on the specific origin of the performance degradation, $\mathrm{Wu}$ et al. recently identified the voltage range where the detrimental reactions occur. According to their STEM/EELS study on the materials cycled at different upper cutoff voltages, the detrimental surface phase transformation and nanophase separation was initiated and exacerbated exclusively between 4.4 and $4.8 \mathrm{~V} .^{32}$ Although the exact mechanism for the performance degradation remains an open question, the detailed surface evolutions unraveled by these microscopy studies certainly have provided indispensable information for eventually solving this problem.

Another important example of how electron microscopy has contributed to the research of intercalation materials is the olivinestructured $\mathrm{LiFePO}_{4}$ (LFP). With its low cost, non-toxicity, excellent thermal stability and environment friendliness, LFP has become one of the most attractive intercalation cathode materials. However, the defects resulting from the site exchange between $\mathrm{Li}$ and $\mathrm{Fe}$ (denoted as $\mathrm{Fe}_{\mathrm{Li}}$ ) block the one-dimensional $\mathrm{Li}^{+}$transport pathways in LFP and limit the electrochemical performance. Knowledge of the concentration and distribution of $\mathrm{Fe}_{\mathrm{Li}}$ in $\mathrm{LFP}$ is critical for optimizing its performance. Although the amount of the anti-site defects can be easily determined using neutron diffraction, the distribution can be studied only using atomic-resolution annular BF-STEM imaging, which has an ultrahigh spatial resolution and is also sensitive to light elements such as lithium., ${ }^{9,10}$ With the aid of this technique, Chung et al. ${ }^{33}$ discovered the localized aggregation behavior of $\mathrm{Fe}_{\mathrm{Li}}{ }^{34}$ On the basis of their observations, a vacancy-driven mechanism was proposed for the formation of the localized defect segregation (Figure 3a). ${ }^{35}$

In addition to unraveling the defect distribution, electron microscopy has also been used for the detailed investigation of the intercalation mechanisms in LFP. Instead of being a single-phase compound, LFP exhibits two coexisting phases during cycling: $\mathrm{LiFePO}_{4}$ and $\mathrm{FePO}_{4}$. The charge/discharge occurs via the migration of the boundary between these two phases. Understanding the $\mathrm{Li}$ insertion/extraction mechanism at this interphase boundary is essential to understanding the electrochemical behavior of LFP. ${ }^{36-39}$
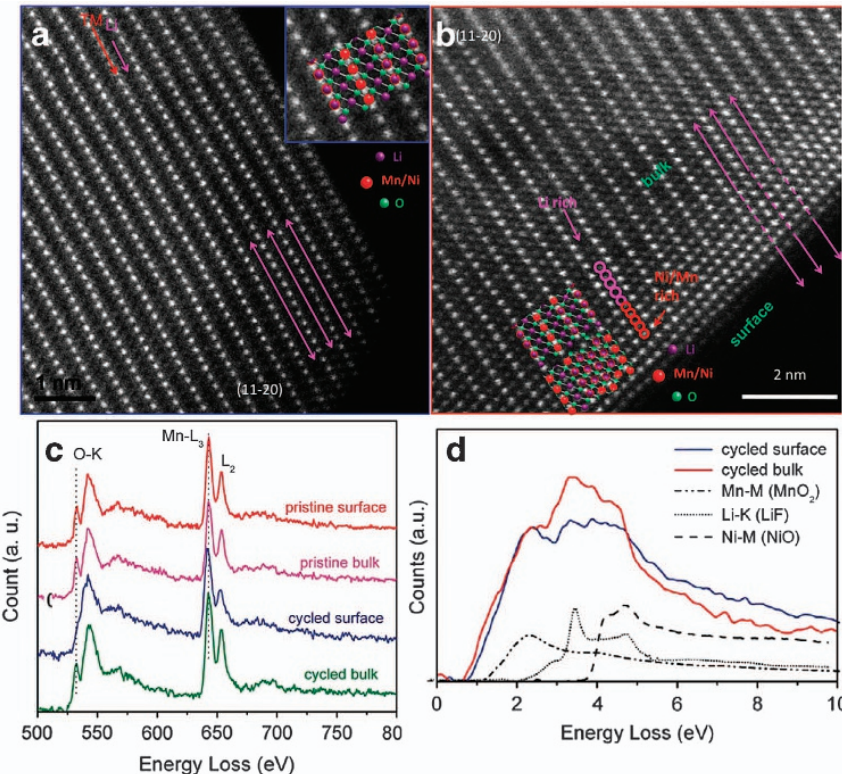

?

e
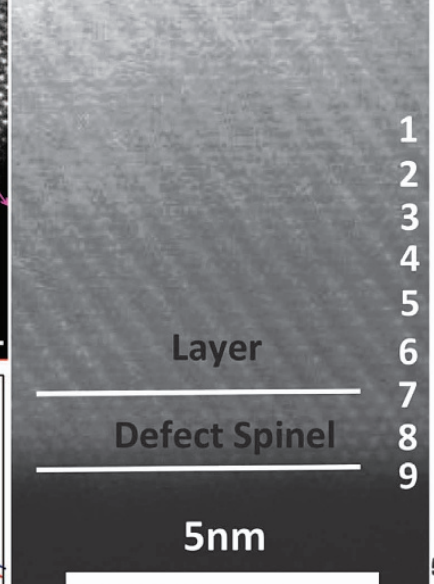

5
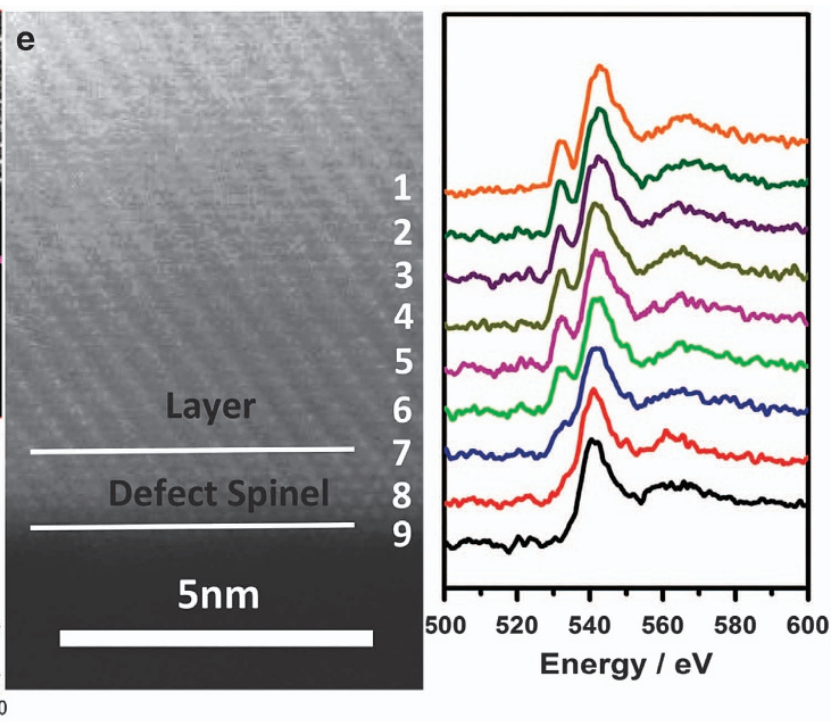

Figure 2 HAADF-STEM images of Li-excess layered materials (a) at the pristine state and (b) after 10 cycles. ${ }^{27}$ (c, d) EELS comparison of the particle surface and bulk for the pristine and cycled materials. ${ }^{26}$ (e) Spatially resolved EELS O-K edges from the surface to the bulk in the cycled Li-excess layered material. ${ }^{29}$ All figures have been reproduced with permission. HAADF, high-angle annular dark field; STEM, scanning transmission electron microscopy. 

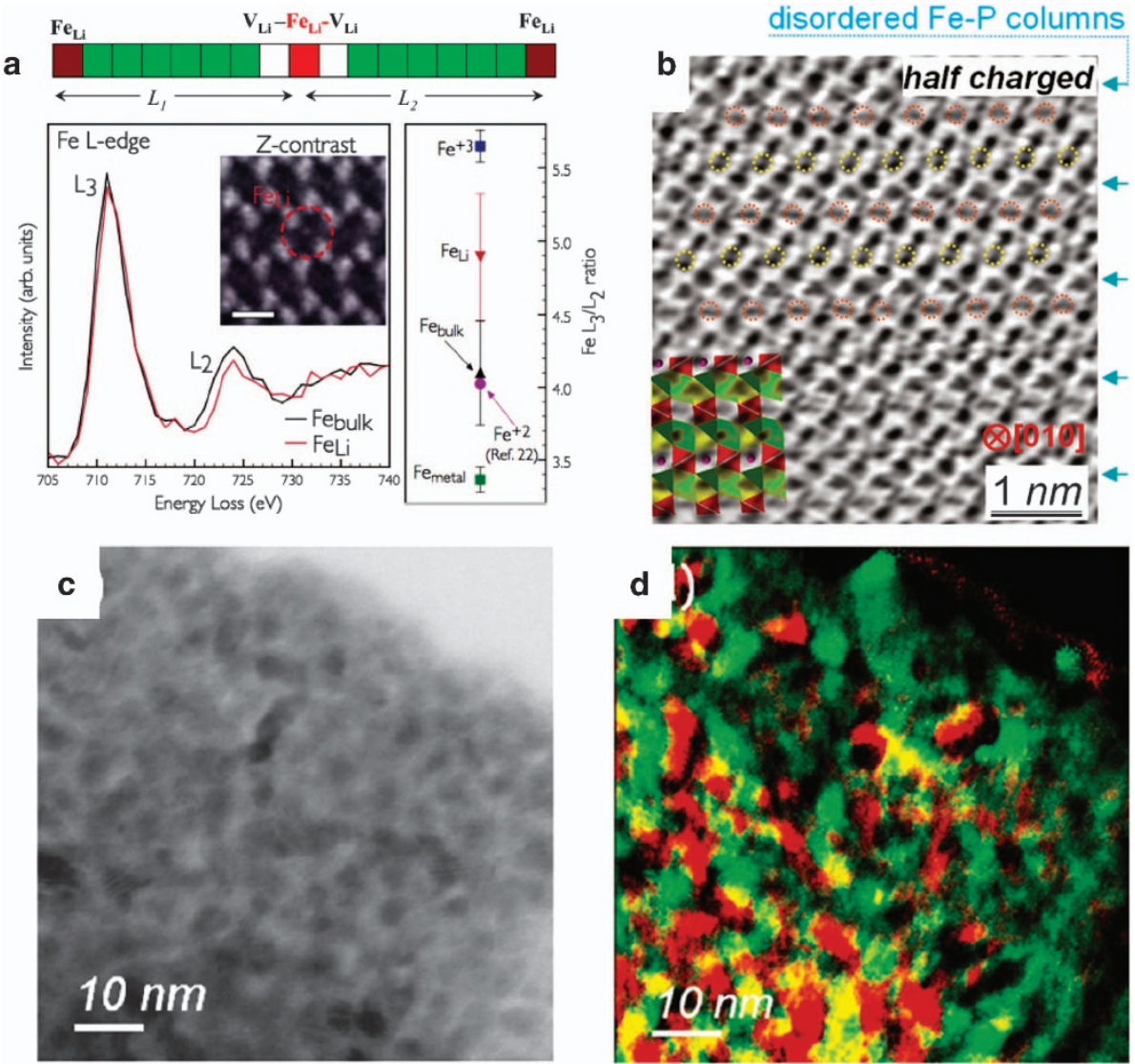

Figure 3 (a) Top: schematic of the probable configuration of $\mathrm{Fe}_{\mathrm{Li}}$ with a higher Fe oxidation state in $\mathrm{LiFePO}_{4}$. Bottom: (left) $\mathrm{EELS}$ data of $\mathrm{Fe}_{\mathrm{Li}}$ and the $\mathrm{Fe}$ in bulk. (right) Compared $\mathrm{Fe} L_{3} / L_{2}$ ratios with different iron compounds as the references. ${ }^{35}$ (b) ABF image of half-charged $\mathrm{LiFePO}_{4}$ showing the $\mathrm{Li}$ staging. ${ }^{70}$ (c) $\mathrm{BF}$ and (d) false-color elemental map of the charged $\mathrm{FeF}_{2}$ with Fe (green) and LiF (red), showing an interconnected network. ${ }^{42}$ All figures have been reproduced with permission.

With a high spatial resolution, electron microscopy studies have been used to determine the initial experimental observations of the phenomenon. Thus, several models, such as the core-shell, ${ }^{37}$ spinodal, ${ }^{38}$ domino cascade models ${ }^{39}$ and so on, were developed to describe the $\mathrm{Li}$ insertion at the $\mathrm{LiFePO}-\mathrm{FePO}_{4}$ boundaries.

Beyond the intercalation materials, electron microscopy is also a valuable asset in the study of conversion and alloying materials. For example, because the cycling of conversion materials typically leads to the formation of metallic nanoparticles and lithium oxide/fluoride, which differ significantly in their average atomic number, the phase conversion process can be directly visualized using Z-contrast HAADFSTEM imaging and the associated elemental mapping (Figures $3 \mathrm{c}$ and d) ${ }^{40-42}$ In addition, the intermediate and final reaction products and volume change of $\mathrm{Si}$, which is the most important alloying anode material, can also be determined by a combination of STEM/EELS and electron diffraction. The results provide valuable insight into the structural and morphological optimization of Si-based materials. ${ }^{43,44}$ Thus, although the conversion and alloying materials have not been as extensively studied as the intercalation materials, advanced electron microscopy is still vital to understanding the microscopic mechanism of their electrochemical behaviors.

\section{Electrolytes}

Due to the safety concerns associated with the flammability and low vapor pressure of conventional carbonate-based liquid electrolytes, stable solid electrolytes have received tremendous attention. ${ }^{45}$
However, the study of solid electrolytes using AEM is challenging. With abundant mobile ions and a small electronic conductivity, the solid electrolytes undergo much more severe electron beam irradiation than the cathode materials. ${ }^{42,46,47}$ As a result, the atomic-resolution (S)TEM studies on solid electrolyte materials are quite rare. ${ }^{44,47-55}$ Regardless, the limited number of papers have provided unique insight into their ionic conduction behaviors and paved the way for the design and discovery of high-performance solid electrolytes.

The primary bottleneck for the application of solid electrolytes is their low conductivity. A rational optimization strategy cannot be formed without a proper understanding of the $\mathrm{Li}^{+}$transport behavior, which consists of the following three aspects: the $\mathrm{Li}^{+}$transport (1) within the lattice (grain interiors), (2) along/across the grain boundaries and (3) across the electrode/electrolyte interfaces. Although the study of the first one has frequently been performed using many different characterization techniques, the other two, in many cases, can be directly studied only by AEM.

The $\mathrm{Li}^{+}$conduction behavior within the lattice is dictated by the presence of $\mathrm{Li}^{+}$percolation pathways. The high spatial resolution and sensitivity to minor structural differences make AEM particularly suitable for studying these features. Using precession electron diffraction, which has the advantage of minimizing the distraction from double diffractions, Buschmann et al. ${ }^{47}$ successfully distinguished between the tetragonal and cubic phases of the garnet, $\mathrm{Li}_{7} \mathrm{La}_{3} \mathrm{Zr}_{2} \mathrm{O}_{12}$ (LLZO). The disordered $\mathrm{Li}$ distribution in the cubic polymorph is essential for explaining its higher ionic conductivity. In the same 
a

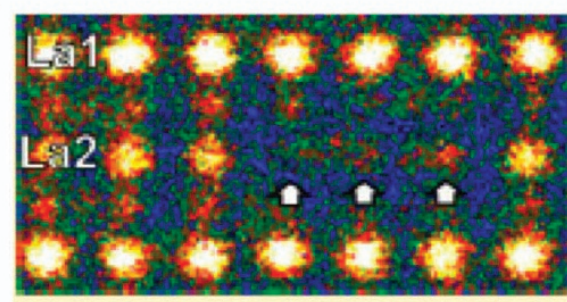

b

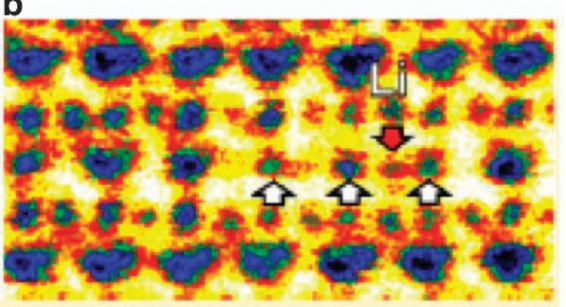

C

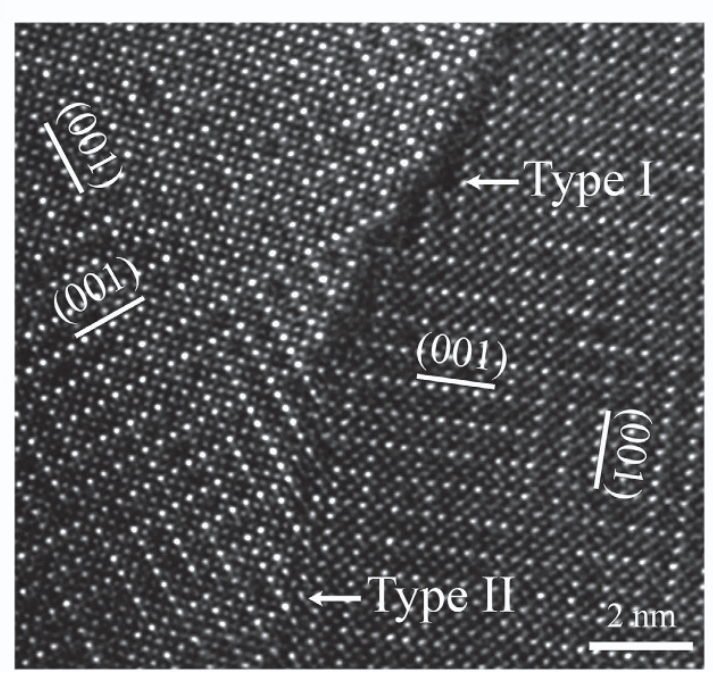

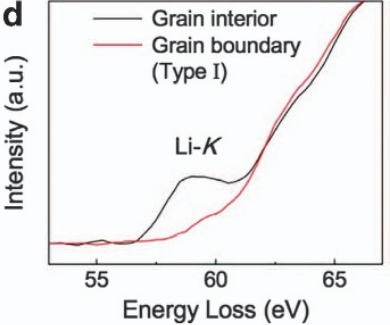

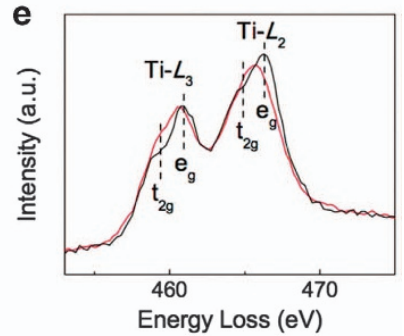

Figure 4 (a) HAADF and (b) ABF images of local clustering of the A-site vacancies and 04 square window lithium in LLTO. ${ }^{55}$ (c) HAADF images of a grain boundary in LLTO. ${ }^{54}$ EELS data of (d) $\mathrm{Li}-K$ and (e) Ti- $L_{2,3}$ edges for the grain boundary and the bulk of LLTO. ${ }^{54}$ All figures have been reproduced with permission. HAADF, high-angle annular dark field.

paper, efforts were also made to study the atomic structure via HRTEM, but only limited information was acquired due to the quick amorphization of the material under the electron beam. Using a low electron beam current and a stable cryogenic sample stage, the difficulty was mitigated in our recent work. ${ }^{53}$ Atomic-resolution HAADF-STEM imaging was, thus, successfully performed on the cubic LLZO ${ }^{53}$ In addition to the overall crystal structure, AEM is also very effective for probing the local chemical variation, such as the $\mathrm{Li}$ distribution, element valence state change, alteration of bond angles and so on. Gao et al. ${ }^{55}$ took advantage of the light-element sensitivity of annular BF-STEM and precisely determined the Li position in $\left(\mathrm{Li}_{3 x} \mathrm{La}_{2 / 3-x}\right) \mathrm{TiO}_{3}$, a system showing the highest bulk conductivity among all of the oxide solid electrolytes (Figures $4 \mathrm{a}$ and b). ${ }^{45}$ Furthermore, the Li content, the valence state of $\mathrm{Ti}$ and the geometry variation of the oxygen octahedra in the alternating La-rich and La-poor layers were revealed via the associated EELS analysis. ${ }^{55}$ The same authors also reported the local structural and chemical variation across the boundaries between the La-rich/poor ordering domains, and they concluded that the domain boundaries serve as obstacles for the Li transport. ${ }^{49}$ The precise analysis of the local features provided invaluable insight for interpreting the ionic conduction mechanism.

Although most studies on solid electrolytes are focused on the $\mathrm{Li}$ transport within the lattice (grain interiors), the grain boundaries are also important. The bulk conductivity of many solid electrolytes is actually sufficiently high for the applications. ${ }^{45}$ It is their large grainboundary resistance that lowers the total conductivity by several orders of magnitude. ${ }^{45}$ Unfortunately, due to the lack of knowledge on the grain-boundary conduction mechanism, no effective optimization strategy has been formed. Because the grain boundaries are typically as thin as several unit cells, the ultrahigh spatial resolution in AEM is an ideal tool to study them. Recently, Ma et al. ${ }^{54}$ was the first to successfully scrutinize the structure and chemistry of the grain boundaries in $\left(\mathrm{Li}_{3 x} \mathrm{La}_{2 / 3-x}\right) \mathrm{TiO}_{3}$ (LLTO), a typical example of a $\mathrm{Li}^{+}$ superionic conductor that is plagued by poor grain-boundary conductivity (Figures 4c-e). A local structural fluctuation at the grain boundaries was found to prohibit the abundance of $\mathrm{Li}$, which hinders the ionic transport. The capability of AEM to resolve these issues has clearly been demonstrated. Nevertheless, there has been little effort devoted to these studies, and the grain-boundary conduction mechanism for many important systems remains unknown.

Finally, AEM is also very effective in the study of interfaces. Similar to the solid-electrolyte interphase (SEI) layer in conventional Li-ion batteries with organic liquid electrolytes, interfacial layers between the intercalation cathodes and the solid electrolytes, i.e. the so-called cathode-electrolyte interphase (CEI), are frequently observed. ${ }^{50-52}$ A fundamental understanding of the structure and chemistry of these interfaces is necessary to optimize battery performance. On the basis of the combined imaging and energy-dispersive X-ray spectroscopy (EDX) analyses, the interface in most systems was found to form via the mutual diffusion between the cathode and solid electrolyte. ${ }^{50-52}$ Unlike the SEI layers in conventional Li-ion batteries, the CEI interfaces are more detrimental than beneficial, and their existence typically introduces a large interfacial resistance and degrades the battery performance. ${ }^{50-52}$

In summary, AEM has provided critical insight into the research of ionic transport in solid electrolyte materials. Its high spatial resolution offers a unique advantage for studying localized features such as grain boundaries and interfaces. However, because the electron radiation 
damage of solid electrolytes is especially difficult to control, currently the atomic-resolution STEM/EELS studies can be performed in only a very limited number of systems. Clearly, the implementation of this powerful tool in the study of solid electrolytes requires a comprehensive investigation of the radiation damage mechanism, which can guide the optimization of the electron beam conditions for each specific system.

\section{DYNAMIC/IN SITU MICROSCOPY FOR BATTERY RESEARCH}

Because of the dynamic nature of electrochemical processes, it is important to reveal the real-time structural and chemical changes in battery materials under relevant operating conditions. This task demands in situ analysis. Compared with the macroscopic in situ analysis techniques, in situ (S)TEM-based methods directly visualize material behaviors in real time with a high spatial and temporal resolution. However, introducing the operation conditions of real batteries into the column of an electron microscope is challenging. More specifically, at least these three requirements need to be strictly fulfilled: (1) the cell size must fit within the microscope's narrow polepiece gap (typically 5-10 mm), (2) the sample should be sufficiently thin for electron beam transparency, and (3) the cell design must be high-vacuum friendly. In the following sections, the most extensively studied in situ microscopy cell configurations for battery research will be discussed in detail.

\section{Open-cell configuration}

In an open-cell configuration (Figure 5a), the electrolyte is either solid $\mathrm{Li}_{2} \mathrm{O}$ or a low-vapor-pressure ionic liquid (IL) that makes point contact with the cathode. An overpotential is applied to the cathode, and $\mathrm{Li}^{+}$is driven from one electrode to the other. The lithiation process during electrochemical cycling for several electrode materials has been studied using this configuration. ${ }^{56-59}$ Although intercalation materials were also studied, alloying and conversion anode materials have been more frequently studied because the large volume change that is associated with the charge/discharge can be readily detectable even under low magnifications. Liu et al. ${ }^{60}$ reported the direct observation of anisotropic swelling of Si nanowires during lithiation, and a following study further revealed electrochemical-induced fractures on the nanostructured $\mathrm{Si}$ that had different particle sizes. ${ }^{56}$ The lithiation process was observed at the atomic scale, which led to the discovery of a layer-by-layer peeling mechanism for the lithiation on $\mathrm{Si}\{111\}$ facets, ${ }^{57}$ and it explained the orientation-dependent $\mathrm{Li}$ mobility in Si. Wang et al..$^{58}$ studied the lithiation mechanism of amorphous $\mathrm{SnO}_{2}$ nanowires and observed a simultaneous partitioning and coarsening characteristic of $\mathrm{Li}_{x} \mathrm{Sn}$ as a result of $\mathrm{Sn}$ and $\mathrm{Li}$ diffusion. Zhu et al. ${ }^{59}$ imaged the $\mathrm{LiFePO}_{4} / \mathrm{FePO}_{4}$ phase boundary movement during electrochemical cycling for the first time. Wang et al. studied the conversion reaction for $\mathrm{FeF}_{2}$, which was observed to start at the surface and propagate into the bulk in a manner similar to spinodal decomposition. ${ }^{61}$ In addition to the half-cell configuration that uses Li metal as the electrode, full-cell configurations have also been used recently. For example, Huang et al. ${ }^{62}$ used $\mathrm{LiCoO}_{2}$ as the counter electrode to $\mathrm{SnO}_{2}$ and observed a reaction front propagating in the lithiated $\mathrm{SnO}_{2}$ nanowire, as depicted in Figure 5b.

The in situ open-cell configuration has provided invaluable nanoscale information to identify the lithium transport mechanisms

\section{a}

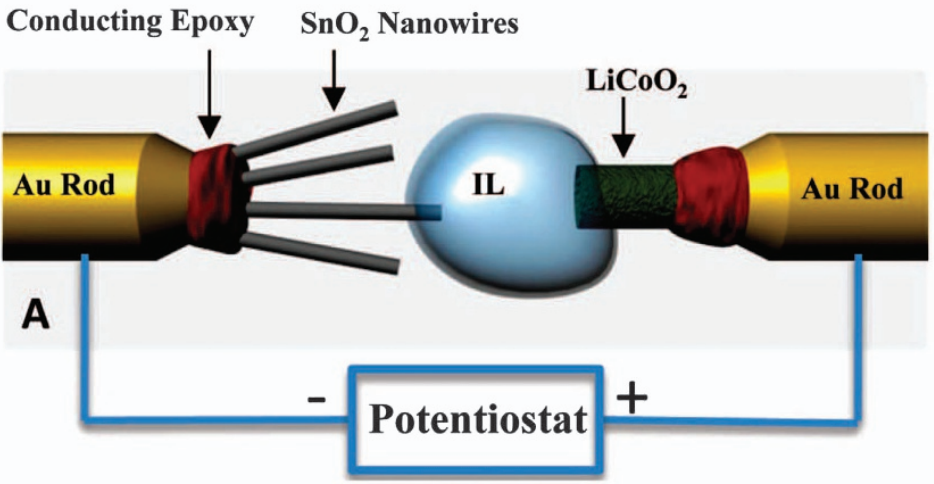

b
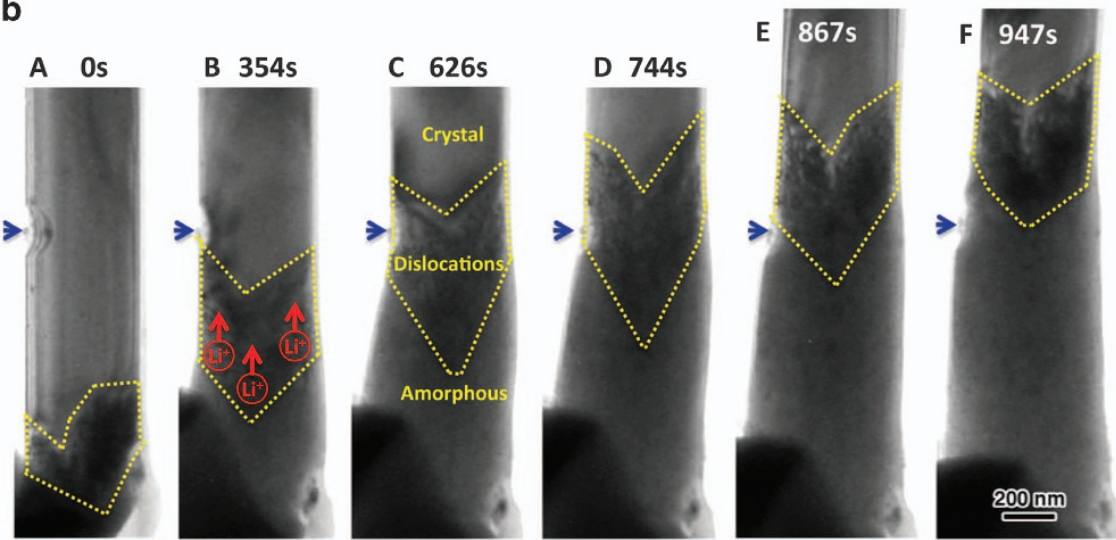

Figure 5 (a) Schematic of the open-cell configuration. ${ }^{62}$ (b) The high density of dislocations emerging from the reaction front was revealed in a single $\mathrm{SnO}_{2}$ nanowire. ${ }^{62}$ All figures have been reproduced with permission. 
in several electrode materials. However, its simple configuration not only limits the selection of materials (especially the electrolytes) but also prevents the simultaneous recording of electrochemical data. Moreover, the cycling is also difficult to control. Therefore, other in situ configurations have been developed to overcome these limitations.

\section{Liquid-cell configuration}

The limitations of the open-cell configuration for in situ microscopy studies stimulated the development of other configurations that can better mimic actual batteries. One promising strategy is the liquid-cell configuration in which a fully functioning miniature battery is sealed with silicon nitride membranes to prevent the evaporation of the liquid electrolyte. In contrast to the open-cell configuration, the liquid-cell configuration not only allows for the integration of commonly used electrolytes but also preserves the intimate electrodeelectrolyte contact in real batteries. It is presently the only electron microscopy technique that enables the in situ observation of the structural and chemical evolution of materials in a electrochemical cell with a high vapor pressure. With these advantages, researchers have acquired valuable insight that was difficult to obtain in the open-cell configuration. When $\mathrm{Gu}$ et al. ${ }^{63}$ applied the liquid-cell configuration to study a battery with a Si nanowire electrode (Figure 6a), they not only observed phenomena that are consistent with the open-cell studies but also successfully unraveled the dynamics of the electrolyte, which is difficult to probe using the open-cell setup. ${ }^{64}$ Following this pioneering work, Zeng et al. ${ }^{22}$ observed Li metal dendritic growth and SEI layer formation (Figures $6 \mathrm{~b}$ and $\mathrm{c}$ ) within a liquid cell. Most recently, Mehdi et al. ${ }^{64}$ took advantage of the dissimilar densities between Li metal and the SEI layer and successfully distinguished the SEI layer and the Li dendrites in their liquid-cell STEM study. In addition, Holtz et al. ${ }^{65}$ used a similar configuration to determine the lithiation state of $\mathrm{LiFePO}_{4}$ in real time with a relatively high spatial resolution. Beyond these discoveries, the liquid-cell configuration also holds potential for further improvements. For example, higher spatial resolution may be achieved by either decreasing the liquid and window thickness or using high-atomic-number anodes and cathodes.

Despite these discoveries, the liquid-cell configuration has several limitations. One of its primary disadvantages is the low spatial resolution. The presence of silicon nitride membranes and the liquid electrolyte reduces the overall electron transparency of the miniature battery. As a result, the liquid-cell configuration is mostly suitable for probing the morphology changes, such as the Li dendrite growth, but cannot directly study the detailed structural and chemical evolution at the atomic scale. Unfortunately, the chemical evolution is typically more essential for understanding the electrode processes. Clearly, preserving the full functions in miniature batteries is not sufficient for a detailed in situ TEM study. Minimizing the additional thickness and maintaining a high spatial resolution are also important.

\section{All-solid-state microbattery}

The all-solid-state microbattery approach can circumvent the disadvantages of the liquid-cell configuration without sacrificing the integrity of the batteries. In this configuration, the focused ion beam (FIB) system is used to fabricate a cross-sectional lamella from an all-solid-state thin-film battery, as shown in Figures 6d-f. The FIB-prepared lamella not only preserves the full function of the thin-film battery but also is thin enough $(\leqslant 100 \mathrm{~nm})$ for electron

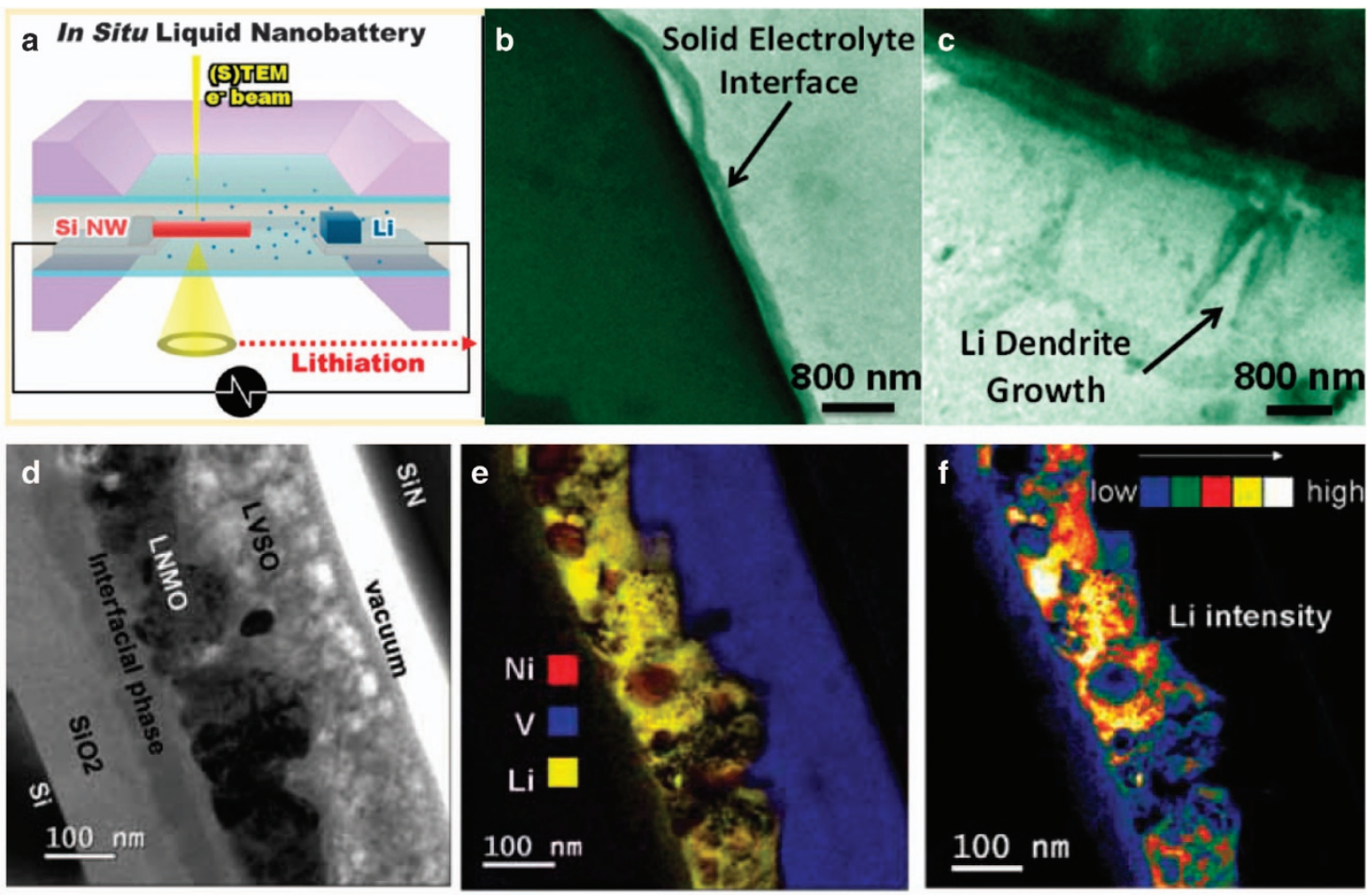

Figure 6 (a) Schematic of the liquid-cell configuration. ${ }^{63}$ (b, c) In situ observation of the inhomogeneous lithiation, the lithium metal dendritic growth, and the solid-electrolyte interface formation. ${ }^{22}$ (d) An example of the all-solid-state microbattery with the configuration of $\mathrm{Au}$ (current collector)/SnO ${ }_{2}$ (anode)/ $\mathrm{Li}_{3.4} \mathrm{~V}_{0.6} \mathrm{Si}_{0.4} \mathrm{O}_{4}$ (electrolyte)/LiNi ${ }_{0.5} \mathrm{Mn}_{1.5} \mathrm{O}_{4}$ (cathode)/Pt (current collector). ${ }^{67}$ (e, f) The EELS mapping of $\mathrm{Ni}, \mathrm{V}, \mathrm{Li}$ and Li intensity of the microbattery in (d). ${ }^{67}$ All figures have been reproduced with permission. 
transparency. Without interference from the silicon nitride membranes and organic electrolytes used in the liquid-cell configuration, the all-solid-state microbattery approach can provide more detailed structural and chemical information at a much higher spatial resolution. In 2010, Yamamoto et al. ${ }^{66}$ successfully applied this configuration to visualize the electric potential variation during the charge/discharge processes for the first time. Using a piece of $90-\mu \mathrm{m}$-thick NASICON-type glass ceramic (Ohara Inc., Kanagawa, Japan) as the electrolyte and 800 -nm-thick $\mathrm{LiCoO}_{2}$ as the cathode, the pristine-state battery was configured as $\mathrm{Au} / \mathrm{LiCoO}_{2} /$ solid electrolyte/Pt. During the first charge, the solid electrolyte region adjacent to the $\mathrm{Pt}$ was reduced, which then served as the anode for the following discharge. With this setup, the two-dimensional potential distribution that resulted from the movement of $\mathrm{Li}^{+}$near the $\mathrm{LiCoO}_{2} /$ solidelectrolyte interface was clearly visualized. This success stimulated an intense interest in the further development and application of the allsolid-state microbattery approach for more in-depth analysis.

Despite its apparent advantages, presently this technique is much less developed than the two previously discussed techniques, and many problems still need to be addressed. First, the small thickness of the microbatteries (usually $100 \mathrm{~nm}$ or less) poses a formidable challenge. Cycling of a Li-ion battery usually demands a current density less than a few or tens of $\mathrm{mAcm}^{-2}$ (otherwise, the battery will fail catastrophically). ${ }^{67}$ Because of the small dimensions of the FIB-prepared lamella needed for TEM observation, an extremely weak current of only a few $\mathrm{pA}$ is required to meet the current-density requirement, and implementing this high current resolution is challenging for most in situ TEM holders. Second, the instability of solid electrolytes creates complications. Although not volatile like the liquid-organic electrolytes, many solid electrolytes are air or moisture sensitive. For example, the most important thin-film electrolyte, LiPON, easily decomposes by reacting with the moisture in air, and almost all sulfide-based solid electrolytes, despite their high conductivity, suffer severely from hydrolysis. ${ }^{45}$ Therefore, appropriate air protection is necessary for specimen transfer and storage outside the vacuum systems of the FIB and AEM. Third, the re-deposition of milled battery materials during FIB fabrication could easily cover both the cathode and anode, shorting the entire microbattery stack. Finally, electron beam induced damage of the battery materials during (S)TEM observation must be minimized and/or eliminated by the careful control of the imaging and analysis conditions. Because of these challenges (and possibly many other unknown difficulties), the full charge/discharge cycle has not been reported since Yamamoto's in situ electron holography study in 2010. Only a few relatively successful attempts have been made. For example, Meng et al. ${ }^{67}$ have performed in situ TEM studies on $\mathrm{Au} / \mathrm{SnO}_{2} / \mathrm{Li}_{3.4} \mathrm{~V}_{0.6} \mathrm{Si}_{0.4} \mathrm{O}_{4} / \mathrm{LiCoO}_{2} / \mathrm{Pt}$ and $\mathrm{Au} / \mathrm{LiCoO}_{2} / \mathrm{LiPON} / \mathrm{Si} / \mathrm{Cu}^{68}$ microbatteries. Although neither of them implemented a full charge/ discharge cycle, the elemental distributions across the interfaces were successfully visualized, and valuable experiences for fabricating a microbattery FIB lamella were obtained. Clearly, the all-solid-state microbattery configuration is still in its infancy compared with the open-cell and liquid-cell approaches. Regardless, this technique exhibits great potential to unravel the atomic-scale structural and chemical evolution during battery operation and is thus attracting increasingly intense interest.

\section{CONCLUSIONS AND PERSPECTIVES}

In this review, we focused on the recent progress in the application of AEM for studying lithium-ion batteries. With the remarkable advancement of the instruments, many of the previously formidable tasks, such as visualizing the distribution of light elements, unraveling the interface structure and chemistry at the atomic scale, probing the SEI layers and so on, are now achievable. Such capabilities have increased the fundamental understanding of the electrochemical behaviors of several important electrode and solid electrolyte materials. In addition to the static and ex situ studies, innovative in situ TEM techniques have also been developed to study the dynamic electrochemical processes during charge/discharge. Among the three categories of the most extensively pursued in situ TEM configurations, the all-solid-state microbattery approach can possibly circumvent the primary limitations of the open-cell and liquid-cell configurations without compromising the battery integrity. These characteristics hold great promise for realizing atomic-scale observations of the dynamic structure and chemical evolution during battery operation, which are keys for understanding and improving battery performances.

\section{CONFLICT OF INTEREST}

The authors declare no conflict of interest.

\section{ACKNOWLEDGEMENTS}

The research was supported by ORNL's Center for Nanophase Materials Sciences (CNMS), which is a U.S. Department of Energy, Office of Science User Facility. D.Q. and Y.S.M. acknowledge the partial funding support from the U.S. Department of Energy, Office of Basic Energy Sciences, \# DE-SC0002357.

1 Erni, R., Lazar, S. \& Browning, N. D. Prospects for analyzing the electronic properties in nanoscale systems by VEELS. Ultramicroscopy 108, 270-276 (2008).

2 Haider, M., Hartel, P., Muller, H., Uhlemann, S. \& Zach, J. Current and future aberration correctors for the improvement of resolution in electron microscopy. Philos. Trans. A Math. Phys. Eng. Sci. 367, 3665-3682 (2009).

3 Kirkland, E. J. On the optimum probe in aberration corrected ADF-STEM Ultramicroscopy 111, 1523-1530 (2011)

4 Lupini, A. R., Krivanek, O. L., Dellby, N., Nellist, P. D. \& Pennycook, S. J. Developments in $\mathrm{C}_{\mathrm{s}}$-corrected STEM. Inst. Phys. Conf. Ser No. 168 31-34 (2001).

5 Peng, Y. P., Nellist, P. D. \& Pennycook, S. J. HAADF-STEM imaging with sub-angstrom probes: a full Bloch wave analysis. J. Electron Microsc. (Tokyo) 53 257-266 (2004)

6 Findlay, S. D., Lugg, N. R., Shibata, N., Allen, L. J. \& Ikuhara, Y. Prospects for lithium imaging using annular bright field scanning transmission electron microscopy: a theoretical study. Ultramicroscopy 111, 1144-1154 (2011).

7 Krumeich, F., Muller, E. \& Wepf, R. A. Phase-contrast imaging in aberration-corrected scanning transmission electron microscopy. Micron 49, 1-14 (2013).

$8 \mathrm{Yu}$, Z. H., Muller, D. A. \& Silcox, J. Study of strain fields at a-Si/c-Si interface. J. Appl. Phys. 95, 3362-3371 (2004).

9 Egerton, R. F. Electron energy-loss spectroscopy in the TEM. Rep. Prog. Phys. 72 016502 (2009).

10 Chi, M. F., Mizoguchi, T., Martin, L. W., Bradley, J. P., Ikeno, H., Ramesh, R., Tanaka, I. \& Browning, N. Atomic and electronic structures of the $\mathrm{SrVO}_{3}-\mathrm{LaAlO}_{3}$ interface. J. Appl. Phys. 110, 046104 (2011).

11 Muller, D. A., Kourkoutis, L. F., Murfitt, M., Song, J. H., Hwang, H. Y., Silcox, J., Dellby, N. \& Krivanek, O. L. Atomic-scale chemical imaging of composition and bonding by aberration-corrected microscopy. Science 319, 1073-1076 (2008).

12 Allen, L. J., Findlay, S. D., Lupini, A. R., Oxley, M. P. \& Pennycook, S. J. Atomic-resolution electron energy loss spectroscopy imaging in aberration corrected scanning transmission electron microscopy. Phys. Rev. Lett. 91 105503 (2003).

13 Krivanek, O. L., Lovejoy, T. C., Dellby, N., Aoki, T., Carpenter, R. W., Rez, P., Soignard, E., Zhu, J. T., Batson, P. E., Lagos, M. J., Egerton, R. F. \& Crozier, P. A Vibrational spectroscopy in the electron microscope. Nature 514, 209-212 (2014).

14 Tang, D. M., Ren, C. L., Wang, M. S., Wei, X. L., Kawamoto, N., Liu, C., Bando, Y. Mitome, M., Fukata, N. \& Golberg, D. Mechanical properties of Si nanowires as revealed by in situ transmission electron microscopy and molecular dynamics simulations. Nano Lett. 12, 1898-1904 (2012).

15 Shan, Z. W. In situ TEM investigation of the mechanical behavior of micronanoscaled metal pillars. JOM 64, 1229-1234 (2012).

16 Liu, J. Y. Advanced electron microscopy of metal-support interactions in supported metal catalysts. ChemCatChem 3, 934-948 (2011).

17 Klein, K. L., Anderson, I. M. \& De Jonge, N. Transmission electron microscopy with a liquid flow cell. J. Microsc. 242, 117-123 (2011). 
18 Park, J., Zheng, H. M., Lee, W.C., Geissler, P. L., Rabani, E. \& Alivisatos, A. P. Direct observation of nanoparticle superlattice formation by using liquid cell transmission electron microscopy. ACS Nano 6, 2078-2085 (2012).

19 Crozier, P. A. \& Chenna, S. In situ analysis of gas composition by electron energy-loss spectroscopy for environmental transmission electron microscopy. Ultramicroscopy $111,177-185$ (2011).

20 Chang, H. J., Kalinin, S. V., Yang, S., Yu, P., Bhattacharya, S., Wu, P. P., Balke, N., Jesse, S., Chen, L. Q., Ramesh, R., Pennycook, S. J. \& Borisevich, A. Y. Watching domains grow: In-situ studies of polarization switching by combined scanning probe and scanning transmission electron microscopy. J. Appl. Phys. 110, 052014 (2011).

21 Yang, Y. C., Gao, P., Gaba, S., Chang, T., Pan, X. Q. \& Lu, W. Observation of conducting filament growth in nanoscale resistive memories. Nat. Commun. 3, 732 (2012).

22 Zeng, Z., Liang, W.-I., Liao, H.-G., Xin, H. L., Chu, Y.-H. \& Zheng, H. Visualization of electrode-electrolyte interfaces in $\mathrm{LiPF}_{6} / \mathrm{EC} / \mathrm{DEC}$ electrolyte for lithium ion batteries via in situ TEM. Nano Lett. 14, 1745-1750 (2014).

23 Jarvis, K. A., Deng, Z., Allard, L. F., Manthiram, A. \& Ferreira, P. J. Atomic structure of a lithium-rich layered oxide material for lithium-ion batteries: evidence of a solid solution. Chem. Mater. 23, 3614-3621 (2011).

24 Bareño, J., Balasubramanian, M., Kang, S. H., Wen, J. G., Lei, C. H., Pol, S. V., Petrov, I. \& Abraham, D. P. Long-range and local structure in the layered oxide $\mathrm{Li}_{1.2} \mathrm{Co}_{0.4} \mathrm{Mn}_{0.4} \mathrm{O}_{2}$. Chem. Mater. 23, 2039-2050 (2011).

25 Boulineau, A., Simonin, L., Colin, J.-F., Canévet, E., Daniel, L. \& Patoux, S. Evolutions of $\mathrm{Li}_{1.2} \mathrm{Mn}_{0.61} \mathrm{Ni}_{0.18} \mathrm{Mg}_{0.01} \mathrm{O}_{2}$ during the initial charge/discharge cycle studied by advanced electron microscopy. Chem. Mater. 24, 3558-3566 (2012).

26 Xu, B., Fell, C. R., Chi, M. \& Meng, Y.S. Identifying surface structural changes in layered Li-excess nickel manganese oxides in high voltage lithium ion batteries: a joint experimental and theoretical study. Energy Environ. Sci. 4, 2223-2233 (2011).

27 Carroll, K. J., Qian, D., Fell, C., Calvin, S., Veith, G. M., Chi, M., Baggetto, L. \& Meng, Y. S. Probing the electrode/electrolyte interface in the lithium excess layered oxide $\mathrm{Li}_{1.2} \mathrm{Ni}_{0.2} \mathrm{Mn}_{0.6} \mathrm{O}_{2}$. Phys. Chem. Chem. Phys. 15, 11128-11138 (2013).

28 Fell, C. R., Qian, D., Carroll, K. J., Chi, M., Jones, J. L. \& Meng, Y. S. Correlation between oxygen vacancy, microstrain, and cation distribution in lithium-excess layered oxides during the first electrochemical cycle. Chem. Mater. 25, 1621-1629 (2013).

29 Qian, D., Xu, B., Chi, M. \& Meng, Y. S. Uncovering the roles of oxygen vacancies in cation migration in lithium excess layered oxides. Phys. Chem. Chem. Phys. 16, 14665-14668 (2014).

30 Boulineau, A., Simonin, L., Colin, J. F., Bourbon, C. \& Patoux, S. First evidence of manganese-nickel segregation and densification upon cycling in Li-rich layered oxides for lithium batteries. Nano Lett. 13, 3857-3863 (2013).

31 Gu, M., Genc, A., Belharouak, I., Wang, D., Amine, K., Thevuthasan, S., Baer, D. R., Zhang, J.-G., Browning, N. D., Liu, J. \& Wang, C. Nanoscale phase separation, cation ordering, and surface chemistry in pristine $\mathrm{Li}_{1.2} \mathrm{Ni}_{0.2} \mathrm{Mn}_{0.6} \mathrm{O}_{2}$ for $\mathrm{Li}$-ion batteries. Chem. Mater. 25, 2319-2326 (2013).

32 Wu, Y., Ma, C., Yang, J., Li, Z., Liang, C., Allard, L. F. \& Chi, M. Probing the initiation of voltage decay in Li-rich layered cathode materials at atomic scale. J. Mater. Chem. A 3, 5385-5391 (2015).

33 Chung, S.-Y., Choi, S.-Y., Yamamoto, T. \& Ikuhara, Y. Orientation-dependent arrangement of antisite defects in lithium iron(II) phosphate crystals. Angew. Chem. Int. Ed. Engl. 48, 543-546 (2009).

34 Janssen, Y., Santhanagopalan, D., Qian, D., Chi, M., Wang, X., Hoffmann, C., Meng, Y. S. \& Khalifah, P. G. Reciprocal salt flux growth of $\mathrm{LiFePO}_{4}$ single crystals with controlled defect concentrations. Chem. Mater. 25, 4574-4584 (2013).

35 Lee, J., Zhou, W., Idrobo, J. C., Pennycook, S. J. \& Pantelides, S. T. Vacancy-driven anisotropic defect distribution in the battery-cathode material $\mathrm{LiFePO}_{4}$. Phys. Rev. Lett. 107, 085507 (2011)

36 Chen, G. Y., Song, X. Y. \& Richardson, T. J. Electron microscopy study of the $\mathrm{LiFePO}_{4}$ to $\mathrm{FePO}_{4}$ phase transition. Electrochem. Solid State Lett. 9, A295-A298 (2006).

37 Laffont, L., Delacourt, C., Gibot, P., Wu, M. Y., Kooyman, P., Masquelier, C. \& Tarascon, J. M. Study of the $\mathrm{LiFePO}_{4} / \mathrm{FePO}_{4}$ two-phase system by high-resolution electron energy loss spectroscopy. Chem. Mater. 18, 5520-5529 (2006).

38 Ramana, C. V., Mauger, A., Gendron, F., Julien, C. M. \& Zaghib, K. Study of the Liinsertion/extraction process in $\mathrm{LiFePO}_{4} / \mathrm{FePO}_{4}$. J. Power Sources 187, 555-564 (2009).

39 Brunetti, G., Robert, D., Bayle-Guillemaud, P., Rouvière, J. L., Rauch, E. F., Martin, J. F., Colin, J. F., Bertin, F. \& Cayron, C. Confirmation of the domino-cascade model by $\mathrm{LiFePO}_{4} / \mathrm{FePO}_{4}$ precession electron diffraction. Chem. Mater. 23, 4515-4524 (2011).

40 Rangan, S., Thorpe, R., Bartynski, R. A., Sina, M., Cosandey, F., Celik, O. \& Mastrogiovanni, D. D. T. Conversion reaction of $\mathrm{FeF}_{2}$ thin films upon exposure to atomic lithium. J. Phys. Chem. C 116, 10498-10503 (2012).

41 Sina, M., Nam, K. W., Su, D., Pereira, N., Yang, X. Q., Amatucci, G. G. \& Cosandey, F. Structural phase transformation and $\mathrm{Fe}$ valence evolution in $\mathrm{FeO}_{x} \mathrm{~F}_{2-x} / \mathrm{C}$ nanocomposite electrodes during lithiation and de-lithiation processes. J. Mater. Chem. A 1, 11629-11640 (2013).

42 Wang, F., Robert, R., Chernova, N. A., Pereira, N., Omenya, F., Badway, F., Hua, X., Ruotolo, M., Zhang, R., Wu, L., Volkov, V., Su, D., Key, B., Whittingham, M. S., Grey, C. P., Amatucci, G. G., Zhu, Y. \& Graetz, J. Conversion reaction mechanisms in lithium ion batteries: study of the binary metal fluoride electrodes. J. Am. Chem. Soc. 133, 18828-18836 (2011)

43 Danet, J., Brousse, T., Rasim, K., Guyomard, D. \& Moreau, P. Valence electron energyloss spectroscopy of silicon negative electrodes for lithium batteries. Phys. Chem. Chem. Phys. 12, 220-226 (2010).
44 Gu, M., Wang, Z., Connell, J. G., Perea, D. E., Lauhon, L. J., Gao, F. \& Wang, C. Electronic origin for the phase transition from amorphous $\mathrm{Li}_{x} \mathrm{Si}$ to crystalline $\mathrm{Li}_{15} \mathrm{Si}_{4}$. ACS Nano 7, 6303-6309 (2013).

45 Takada, K. Progress and prospective of solid-state lithium batteries. Acta Mater. 61, 759-770 (2013).

46 Egerton, R. F., Li, P. \& Malac, M. Radiation damage in the TEM and SEM. Micron 35 399-409 (2004).

47 Buschmann, H., Dolle, J., Berendts, S., Kuhn, A., Bottke, P., Wilkening, M., Heitjans, P., Senyshyn, A., Ehrenberg, H., Lotnyk, A., Duppel, V., Kienle, L. \& Janek, J. Structure and dynamics of the fast lithium ion conductor ' $\mathrm{Li}_{7} \mathrm{La}_{3} \mathrm{Zr}_{2} \mathrm{O}_{12}$ '. Phys. Chem. Chem. Phys. 13, 19378-19392 (2011).

48 Kumazaki, S., Iriyama, Y., Kim, K.-H., Murugan, R., Tanabe, K., Yamamoto, K., Hirayama, T. \& Ogumi, Z. High lithium ion conductive $\mathrm{Li}_{7} \mathrm{La}_{3} \mathrm{Zr}_{2} \mathrm{O}_{12}$ by inclusion of both Al and Si. Electrochem. Commun. 13, 509-512 (2011).

49 Gao, X., Fisher, C. A. J., Kimura, T., Ikuhara, Y. H., Kuwabara, A., Moriwake, H., Oki, H., Tojigamori, T., Kohama, K. \& Ikuhara, Y. Domain boundary structures in lanthanum lithium titanates. J. Mater. Chem. A 2, 843-852 (2014).

50 Kim, K. H., Iriyama, Y., Yamamoto, K., Kumazaki, S., Asaka, T., Tanabe, K., Fisher, C. A. J., Hirayama, T., Murugan, R. \& Ogumi, Z. Characterization of the interface between $\mathrm{LiCoO}_{2}$ and $\mathrm{Li}_{7} \mathrm{La}_{3} \mathrm{Zr}_{2} \mathrm{O}_{12}$ in an all-solid-state rechargeable lithium battery. J. Power Sources 196, 764-767 (2011).

51 Sakuda, A., Hayashi, A. \& Tatsumisago, M. Interfacial observation between $\mathrm{LiCoO}_{2}$ electrode and $\mathrm{Li}_{2} \mathrm{~S}-\mathrm{P}_{2} \mathrm{~S}_{5}$ solid electrolytes of all-solid-state lithium secondary batteries using transmission electron microscopy. Chem. Mater. 22, 949-956 (2009).

52 Kitaura, H., Hayashi, A., Tadanaga, K. \& Tatsumisago, M. All-solid-state lithium secondary batteries using $\mathrm{LiMn}_{2} \mathrm{O}_{4}$ electrode and $\mathrm{Li}_{2} \mathrm{~S}_{-}-\mathrm{P}_{2} \mathrm{~S}_{5}$ solid electrolyte. J. Electrochem. Soc. 157, A407-A411 (2010).

$53 \mathrm{Ma}$, C., Rangasamy, E., Liang, C., Sakamoto, J., More, K. L. \& Chi, M. Excellent stability of a lithium-ion-conducting solid electrolyte upon reversible $\mathrm{Li}^{+} / \mathrm{H}^{+}$exchange in aqueous solutions. Angew. Chem. Int. Ed. 54, 129-133 (2015).

54 Ma, C., Chen, K., Liang, C. D., Nan, C. W., Ishikawa, R., More, K. \& Chi, M. F. Atomic-scale origin of the large grain-boundary resistance in perovskite Li-ion-conducting solid electrolytes. Energy Environ. Sci 7, 1638-1642 (2014).

55 Gao, X., Fisher, C. A. J., Kimura, T., Ikuhara, Y. H., Moriwake, H., Kuwabara, A., Oki, H., Tojigamori, T., Huang, R. \& Ikuhara, Y. Lithium atom and A-site vacancy distributions in lanthanum lithium titanate. Chem. Mater. 25, 1607-1614 (2013).

56 Liu, X. H., Zhong, L., Huang, S., Mao, S. X., Zhu, T. \& Huang, J. Y. Size-dependent fracture of silicon nanoparticles during lithiation. ACS Nano 6, 1522-1531 (2012).

57 Liu, X. H., Wang, J. W., Huang, S., Fan, F., Huang, X., Liu, Y., Krylyuk, S., Yoo, J., Dayeh, S. A., Davydov, A. V., Mao, S. X., Picraux, S. T., Zhang, S., Li, J., Zhu, T. \& Huang, J. Y. In situ atomic-scale imaging of electrochemical lithiation in silicon. Nat. Nanotechnol. 7, 749-756 (2012).

58 Wang, C. M., Xu, W., Liu, J., Zhang, J. G., Saraf, L. V., Arey, B. W., Choi, D. W., Yang, Z. G., Xiao, J., Thevuthasan, S. \& Baer, D. R. In situ transmission electron microscopy observation of microstructure and phase evolution in a $\mathrm{SnO}_{2}$ nanowire during lithium intercalation. Nano Lett. 11, 1874-1880 (2011).

59 Zhu, Y., Wang, J. W., Liu, Y., Liu, X., Kushima, A., Liu, Y., Xu, Y., Mao, S. X., Li, J., Wang, C. \& Huang, J. Y. In situ atomic-scale imaging of phase boundary migration in $\mathrm{FePO}_{4}$ microparticles during electrochemical lithiation. Adv. Mater. 25, 5461-5466 (2013).

60 Liu, X. H., Zheng, H., Zhong, L., Huang, S., Karki, K., Zhang, L. Q., Liu, Y., Kushima, A., Liang, W. T., Wang, J. W., Cho, J.-H., Epstein, E., Dayeh, S. A., Picraux, S. T., Zhu, T., Li, J., Sullivan, J. P., Cumings, J., Wang, C., Mao, S. X., Ye, Z. Z., Zhang, S. \& Huang, J. Y. Anisotropic swelling and fracture of silicon nanowires during lithiation. Nano Lett. 11, 3312-3318 (2011).

61 Wang, F., Yu, H.-C., Chen, M.-H., Wu, L., Pereira, N., Thornton, K., Van der Ven, A., Zhu, Y., Amatucci, G.G. \& Graetz, J. Tracking lithium transport and electrochemical reactions in nanoparticles. Nat. Commun. 3, 1201 (2012)

62 Huang, J. Y., Zhong, L., Wang, C. M., Sullivan, J. P., Xu, W., Zhang, L. Q., Mao, S. X., Hudak, N. S., Liu, X. H., Subramanian, A., Fan, H., Qi, L., Kushima, A. \& Li, J. In situ observation of the electrochemical lithiation of a single $\mathrm{SnO}_{2}$ nanowire electrode. Science 330, 1515-1520 (2010).

63 Gu, M., Parent, L. R., Mehdi, B. L., Unocic, R. R., McDowell, M. T., Sacci, R. L., Xu, W., Connell, J. G., Xu, P. H., Abellan, P., Chen, X. L., Zhang, Y. H., Perea, D. E., Evans, J. E., Lauhon, L. J., Zhang, J. G., Liu, J., Browning, N. D., Cui, Y., Arslan, I. \& Wang, C. M. Demonstration of an electrochemical liquid cell for operando transmission electron microscopy observation of the lithiation/delithiation behavior of Si nanowire battery anodes. Nano Lett. 13, 6106-6112 (2013).

64 Mehdi, B. L., Qian, J., Nasybulin, E., Park, C., Welch, D. A., Faller, R., Mehta, H., Henderson, W. A., Xu, W., Wang, C.M., Evans, J. E., Liu, J., Zhang, J. G., Mueller, K. T. \& Browning, N. D. Observation and quantification of nanoscale processes in lithium batteries by operando electrochemical (S)TEM. Nano Lett. 15, 2168-2173 (2015).

65 Holtz, M. E., Yu, Y., Gunceler, D., Gao, J., Sundararaman, R., Schwarz, K. A., Arias, T. A., Abruña, H. D. \& Muller, D. A. Nanoscale imaging of lithium ion distribution during in situ operation of battery electrode and electrolyte. Nano Lett. 14 1453-1459 (2014).

66 Yamamoto, K., Iriyama, Y., Asaka, T., Hirayama, T., Fujita, H., Fisher, C. A. J., Nonaka, K., Sugita, Y. \& Ogumi, Z. Dynamic visualization of the electric potential in an all-solid-state rechargeable lithium battery. Angew. Chem. Int. Ed. Engl. 49, 4414-4417 (2010).

67 Meng, Y. S., McGilvray, T., Ming-Che, Y., Gostovic, D., Feng, W., Dongli, Z., Yintei, Z. \& Graetz, J. In situ analytical electron microscopy for probing nanoscale electrochemistry. Electrochem. Soc. Interface 20, 49-53 (2011). 
68 Santhanagopalan, D., Qian, D., McGilvray, T., Wang, Z. Y., Wang, F., Camino, F. Graetz, J., Dudney, N. \& Meng, Y. S. Interface limited lithium transport in solid-state batteries. J. Phys. Chem. Lett. 5, 298-303 (2014).

69 Zheng, J. M., Gu, M., Genc, A., Xiao, J., Xu, P. H., Chen, X. L., Zhu, Z. H., Zhao, W. B. Pullan, L., Wang, C. M. \& Zhang, J. G. Mitigating voltage fade in cathode materials by improving the atomic level uniformity of elemental distribution. Nano Lett. 14, 2628-2635 (2014).

70 Gu, L., Zhu, C. B., Li, H., Yu, Y., Li, C. L., Tsukimoto, S., Maier, J. \& Ikuhara, Y. Direct observation of lithium staging in partially delithiated $\mathrm{LiFePO}_{4}$ at atomic resolution. J. Am. Chem. Soc. 133, 4661-4663 (2011). (c) (i) This work is licensed under a Creative Commons Attribution 4.0 International License. The images or other third party material in this article are included in the article's Creative Commons license, unless indicated otherwise in the credit line; if the material is not included under the Creative Commons license, users will need to obtain permission from the license holder to reproduce the material. To view a copy of this license, visit http:// creativecommons.org/licenses/by/4.0/ 


\section{GRAPHICAL ABSTRACT}

Advanced analytical electron microscopy for lithium-ion batteries

Danna Qian, Cheng Ma, Karren L More, Ying Shirley Meng and Miaofang Chi

This review highlights the recent developments and contributions of advanced electron microscopy studies to the research of lithium-ion battery materials. Both static, ex situ studies and newly developed in situ AEM techniques are emphasized, and future directions are also proposed.

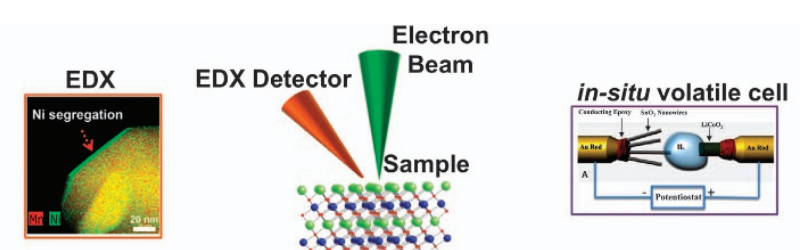

in-situ non-volatile cell

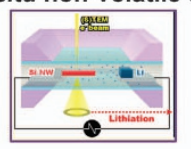

EELS
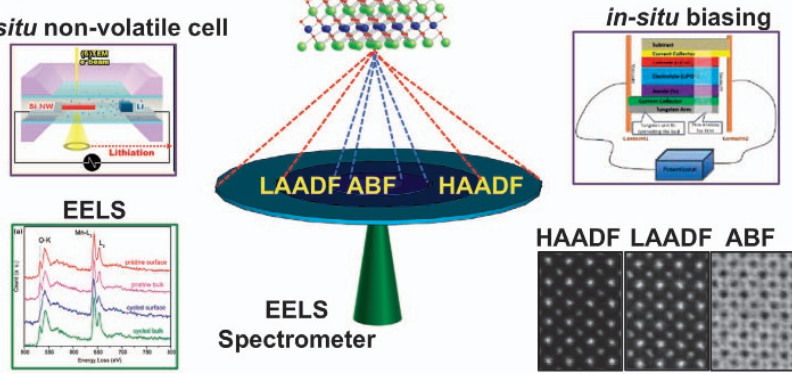

EELS

Spectrometer 